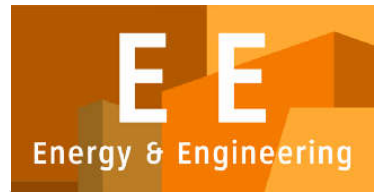

PAPER - OPEN ACCESS

\title{
Analisis Manual Material Handling Menggunakan Pada Pekerja Warehouse KRA PT Pamapersada Nusantara Menggunakan Metode Biomekanika
}

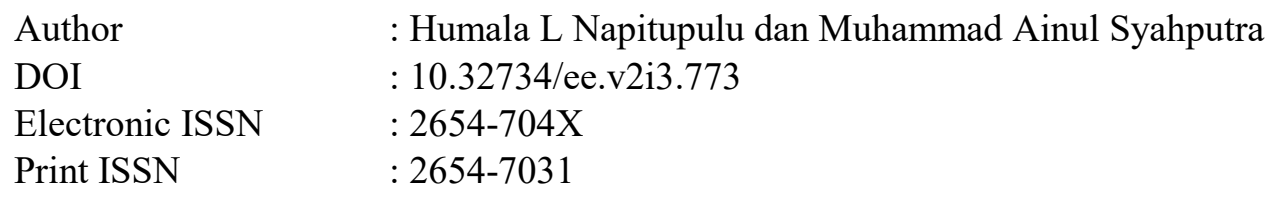

Volume 2 Issue 3 - 2019 TALENTA Conference Series: Energy \& Engineering (EE)

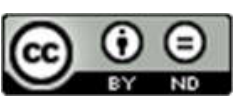

This work is licensed under a Creative Commons Attribution-NoDerivatives 4.0 International License.

Published under licence by TALENTA Publisher, Universitas Sumatera Utara

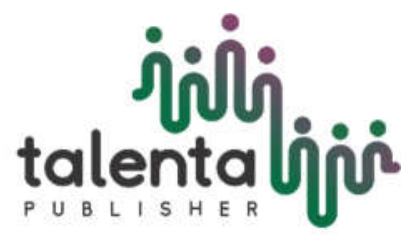




\title{
jidibi (1) \\ EE Conference Series 02 (2019)

\section{Analisis Manual Material Handling Menggunakan Pada Pekerja Warehouse KRA PT Pamapersada Nusantara Menggunakan Metode Biomekanika}

\author{
Humala L Napitupulu ${ }^{1}$ dan Muhammad Ainul Syahputra ${ }^{2}$ \\ 1,2Departemen Teknik Industri, Fakultas Teknik, Universitas Sumatera Utara \\ ${ }^{2}$ muhammadainul183@gmail.com
}

\begin{abstract}
Abstrak
Kerja atau aktivitas merupakan salah satu kegiatan manusia yang tidak dapat dihindarkan lagi. Salah satu aktivitas tersebut adalah pemindahan barang, proses pemindahan barang terjadi baik diperusahaan maupun pekerja yang berada diluar perusahaan. Aktivitas pemindahan yang terjadi pada karyawan di bagian Warehouase KRA PT Pamapersada Nusantara Distrik BAYA secara manual. Aktivitas perpindahan bahan secara manual (Manual Material Handling) pada Warehouse KRA PT. Pamapersada Nusantara Distrik BAYA yang meliputi aktivitas mendorong, mengangkat, menarik dan membawa dimana hal tersebut dilakukan secara terus menerus dan repetitif. Aktivitas pengangkatan sparepart secara membungkuk yang disebabkan adanya pembebanan yang terlalu berat memungkinkan cedera tulang belakang dan gangguan otot lainnya (musculoskeletal disorder). Selain itu aktivitas pemindahan barang (sparepart) juga perlu diperhatikan guna meningkatkan kesehatan dan keselamatan kerja. Pada hasil penelitian berdasarkan perhitungan momen gaya nilai Fc operator 1 sebesar $5647.17 \mathrm{~N}$, Fc operator 2 sebesar $2522.30 \mathrm{~N}$, Fc operator 3 sebesar 4595.21 N, Fc operator 4 sebesar 7645.30 N. Untuk nilai Fc operator 4 lebih besar dari $6500 \mathrm{~N}$, maka kegiatan pemindahan sparepart dikategorikan berbahaya, Fc Operator 1 dan 3 lebih besar dari $3500 \mathrm{~N}$ dan lebih kecil dari $6500 \mathrm{~N}$, maka kegiatan pemindahan sparepart dikategorikan berhati hati, Pada nilai Fc operator 2 lebih kecil $3500 \mathrm{~N}$, maka kegiatan tersebut dikategorikan aman. Dari hasil perhitungan Recommended Weight Limit (RWL) diperoleh nilai origin and destination pada operator 1 sebesar $10.1245 \mathrm{~N}$ dan $8.0993 \mathrm{~N}$, operator 2 sebesar $10.1245 \mathrm{~N}$ dan $8.0896 \mathrm{~N}$, operator 3 sebesar $8.6775 \mathrm{~N}$ dan $7.1866 \mathrm{~N}$, operator 4 sebesar 10.1245 dan $8.0969 \mathrm{~N}$ dan Dari hasil perhitungan nilai origin and destination Lifting Index (LI) pada operator 1 sebesar $1.9754 \mathrm{~N}$ dan $2.4693 \mathrm{~N}$, operator 2 sebesar $1.9754 \mathrm{~N}$ dan $2.4723 \mathrm{~N}$, operator 3 sebesar $2.3048 \mathrm{~N}$ dan $2.7829 \mathrm{~N}$, operator 4 sebesar $1.9754 \mathrm{~N}$ dan 2,4700 N. Berdasarkan hasil Lifting Index (LI) yang diperoleh ialah lebih besar dari 1 dan lebih kecil dari 3, maka kegiatan pemindahan sparepart mengandung resiko cedera pada bagian tulang belakang L5/S1.
\end{abstract}

Kata Kunci: Biomekanika, Lifting Index (LI), Manual Material Hadling, Recommended Weight Limit (RWL).

\begin{abstract}
Work or activity is one of human activities which cannot be avoided anymore. One of these activities is the removal of goods, the process of moving goods occurs both in the company and workers who are outside the company. Transfer activities that occur to employees in the PT Pamapersada Nusantara BAYA District KRA Warehouase manually. Manual material handling activity at KRA Warehouse PT. Pamapersada Nusantara, BAYA District, which includes pushing, lifting, pulling and carrying activities where it is carried out continuously and reactively. The activity of lifting the spare parts by bending due to the imposition of too much weight allows spinal injury and other muscular disorders (musculoskeletal disorder). Besides the activity of moving goods (spare parts) also need to be considered in order to improve work health and safety. Based on the results of the study based on force moment calculation, the value of Fc operator 1 is $5647.17 \mathrm{~N}$, Fc operator 2 is $2522.30 \mathrm{~N}$, Fc operator 3 is $4595.21 \mathrm{~N}$, Fc operator 4 is 7645.30 N. For Fc operator 4 value is greater than $6500 \mathrm{~N}$, the transfer activity spare parts are categorized as dangerous, Fc Operators 1 and 3 are greater than $3500 \mathrm{~N}$ and smaller than $6500 \mathrm{~N}$, then spare part removal activities are categorized cautious, the Fc operator 2 value is smaller than $3500 \mathrm{~N}$, then the activity is categorized safe. From the calculation of the Recommended Weight Limit (RWL), the origin and destination values for operator 1 are 10,1245 N and 8,0993 N, operator 2 are 10,1245 N and $8,0896 \mathrm{~N}$, operator 3 are 8,6775 $\mathrm{N}$ and $7.1866 \mathrm{~N}$, operator 4 is 10,1245 and 8,0969 $\mathrm{N}$ and From the calculation of the origin and destination Lifting Index (LI) value for operator 1 is 1,9754 N and 2,4693 N, operator 2 is 1,9754 N and 2,4723 N, operator 3 is 2,3048 $\mathrm{N}$ and 2,7829 $\mathrm{N}$, operator 4 is 1,9754 $\mathrm{N}$ and 2,4700 N Based on the results of the Lifting Index (LI) obtained is greater than 1 and smaller than 3, the spare part removal activities contain the risk of injury to the L5 / S1 spine.
\end{abstract}

(C) 2019 The Authors. Published by TALENTA Publisher Universitas Sumatera Utara

Selection and peer-review under responsibility of The 3nd National Conference on Industrial Engineering (NCIE)

2019

p-ISSN: 2654-7031, e-ISSN: 2654-704X, DOI: 10.32734/ee.v2i3.773 
Keywords: Biomechanics, Lifting Index (LI), Manual Material Handling, Recommended Weight Limit (RWL).

\section{Pendahuluan}

Aktivitas pemindahan bahan secara manual (Manual Material Handling) yang meliputi aktivitas mendorong, menurunkan, mengangkat, menarik dan membawa adalah penyebab utama keluhan karyawan di perusahaan [1]. Naiknya tingkat cedera atau kecelakaan dapat menyebabkan sakit atau keluhan pada pekerja yang berujung pada menurunnya produktivitas kerja pekerja dan perusahaan, selain itu juga berdampak personal terhadap pekerja yang berhubungan dengan gangguan sistem kerangka otot manusia [2,3,4]. Selain kerugian secara fisik juga menyebabkan kerugian secara materi melalui beban biaya pengobatan yang cukup tinggi dan juga ketidakhadiran pekerja serta penurunan dalam kualitas kerja $[5,6]$.

Sebagian besar pekerja dalam melakukan pekerjaannya, postur kerjanya tidak ergonomis atau tidak sesuai dengan prinsip-prinsip ergonomi yaitu tulang belakang terlalu membungkuk, jangkauan yang melebihi panjang jangkauan tangan pekerja, peralatan kerja yang kurang sesuai dengan ukuran antropometri, sehingga menimbulkan ketidaksesuaian antara pekerja dengan peralatan dan lingkungan kerjanya. Perusahaan tempat penelitian adalah sebuah perusahaan yang bergerak dalam bidang pertambangan batubara, dimana penelitian dilakukan pada bagian Warehouse KRA PT Pamapersada Nusantara Distrik BAYA.

Dari latar belakang masalah diatas, maka yang menjadi pokok masalah untuk dirumuskan dalam penelitian ini adalah untuk merekomendasikan pola akitivitas pemindahan sparepart dengan mempertimbangkan postur kerja pengakatan dengan memberhitungan antara lain, berapa momen gaya, berapa nilai RWL dan LI yang seharusnya diangkat oleh pekerja, apakah pekerja beresiko atau tidak beresiko serta bagaimana usulan perbaikan terhadap pengaruh tulang belakang pada pekerja bongkar terhadap beban-beban yang diangkat selama ini $[7,8]$.

Dalam penelitian ini tujuan yang ingin dicapai yaitu untuk menentukan besarnya momen gaya dan nilai konsumsi energi pada pekerja pemindahan sparepart di Warehouse KRA PT Pamapersada Nusantara Distrik BAYA, untuk mengetahui nilai RWL (Recommended Weight Limit) dan LI (Lifting Index) dan mengetahui apakah aktivitas yang dilakukan menimbulkan resiko atau berada dalam batasan aman.

\section{Metodologi Penelitian}

Obyek penelitian ini ialah pada aktivitas pemindahan sparepart di bagian Warehouase KRA PT Pamapersada Nusantara Distrik BAYA yang beralamat Desa Bhuana Jaya, Kecamatan Tenggarong Seberang, Kabupaten Kutai Kartanegara, Samarinda, Kalimantan Timur. Aktivitas pemindahan sparepart rata rata seberat $20 \mathrm{~kg}$ secara manual. Pekerja yang diamati sebanyak 4 orang, data yang diambil meliputi berat badan pekerja, berat beban yang diangkat, panjang segmen tubuh panjang telapak tangan, lengan atas, lengan bawah, punggung, sudut inklinasi perut terhadap horizontal dan sudut inklinasi paha/punggung terhadap horizontal $[9,10]$. Penelitian ini dilakukan untuk mengetahui beban maksimal yang diangkat oleh pekerja pemindahan sparepart, mengetahui momen gaya digunakan sebagai penentuan batas maksimal yang dapat diangkat oleh pekerja $[11,12]$.

\section{Hasil dan Pembahasan}

Dalam penelitian ini, peneliti menggunakan 3 teknik pengumpulan data, yaitu : :

1. Wawancara

Yaitu salah satu dari sekiat teknik pengumpulan data yang pelaksanaannya dapat dilakukan secara langsung dengan bertanya kepada key informan. Peneliti secara langsung mewawancarai salah satu pekerja pemindahan sparepart.

2. Observasi

Yaitu pengamatan secara langsung terhadap kejadian-kejadian yang ditemukan dilapangan. Kejadian ini dicatat dan didokumentasikan sebagai data penelitian. Yaitu tentang proses kerja yang dilakukan dengan cara manual.

3. Dokumentasi

Merupakan teknik yang bisa digunakan dalam penelitian kualitatif. Dokumentasi merupakan pengumpulanpengumpulan data berupa gambar-gambar, foto-foto, artikel, yang hasilnya dapat dilihat pada table dan gambar berikut 
Tabel 1. Pengumpulan Data Pekerja

\begin{tabular}{|c|c|c|c|c|c|c|c|c|c|c|c|}
\hline \multirow{2}{*}{ Operator } & \multirow{2}{*}{ Metode } & \multicolumn{5}{|c|}{ Sudut Inklinasi } & \multirow{2}{*}{$\begin{array}{l}\text { SL1 } \\
(\mathbf{c m})\end{array}$} & \multirow{2}{*}{$\begin{array}{l}\text { SL2 } \\
\text { (cm) }\end{array}$} & \multirow{2}{*}{$\begin{array}{l}\text { SL3 } \\
(\mathbf{c m})\end{array}$} & \multirow{2}{*}{$\begin{array}{l}\text { SL4 } \\
(\mathbf{c m})\end{array}$} & \multirow{2}{*}{$\begin{array}{c}\text { BB } \\
(\mathrm{kg})\end{array}$} \\
\hline & & $\theta 1$ & $\boldsymbol{\theta 2}$ & O3 & O4 & $\theta 5$ & & & & & \\
\hline 1 & Pemindahan & 64 & 68 & 73 & 30 & 98 & 7 & 28 & 32 & 49 & 59 \\
\hline 2 & Pemindahan & 65 & 70 & 45 & 85 & 80 & 8 & 25 & 30 & 50 & 75 \\
\hline 3 & Pemindahan & 65 & 67 & 70 & 50 & 88 & 8 & 27 & 32 & 50 & 59 \\
\hline 4 & Pemindahan & 65 & 70 & 73 & 30 & 98 & 10 & 29 & 36 & 59 & 76 \\
\hline
\end{tabular}

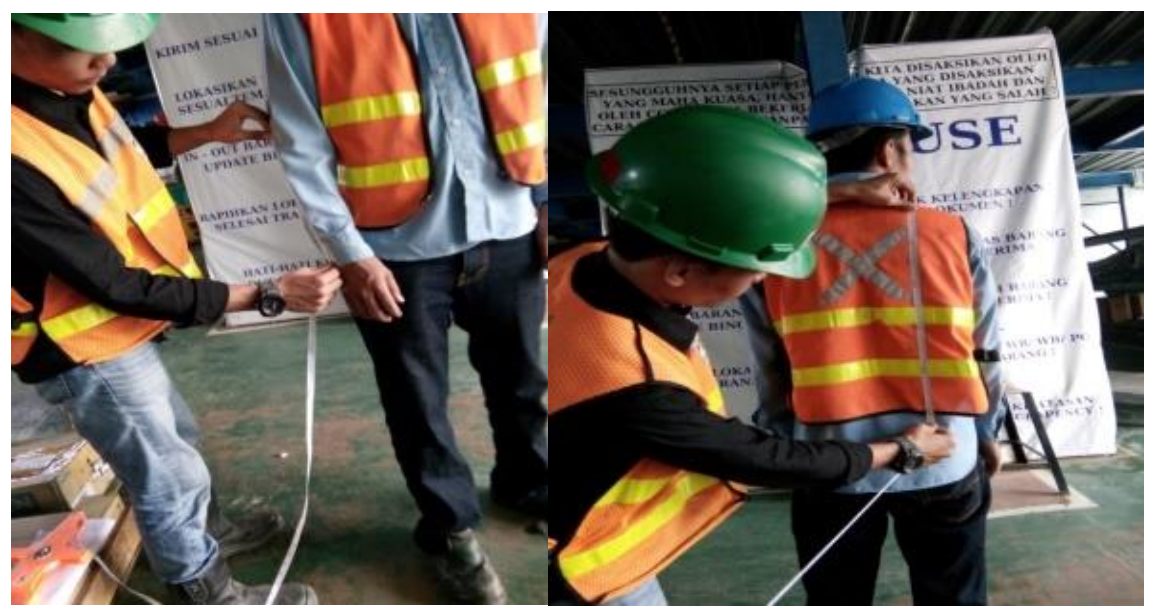

Gambar 1. Pengumpulan data antropometri

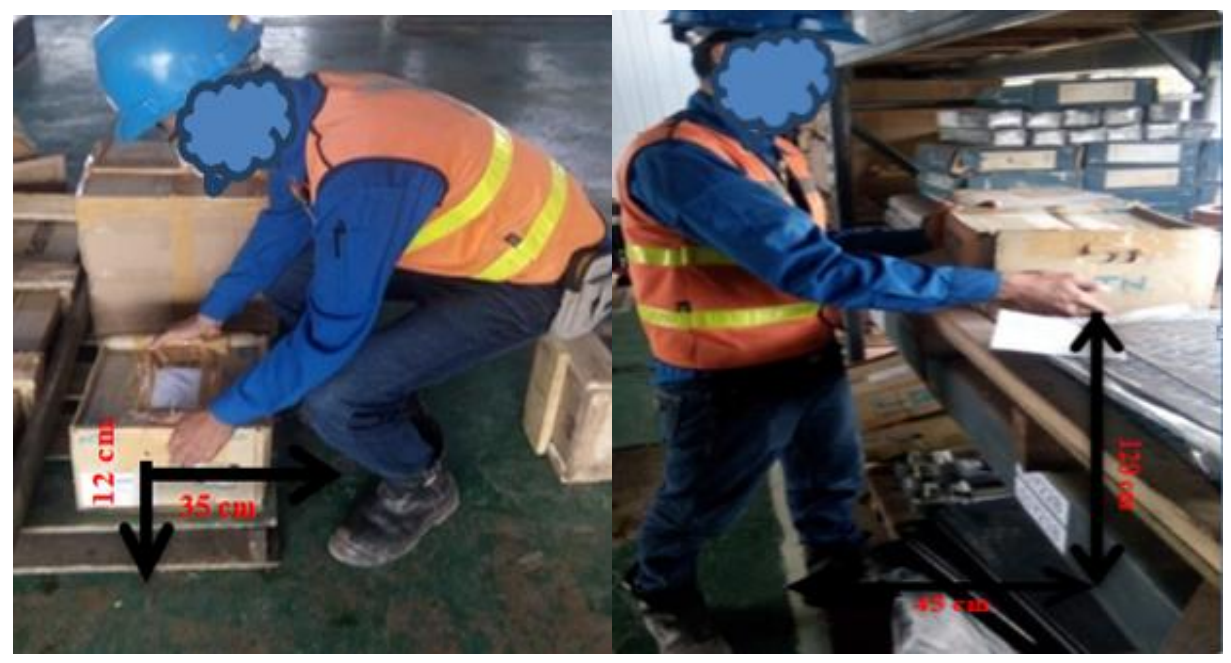

Gambar 2. Pengumpulan data waktu pemindahan

Untuk pengolahan data terdiri dari beberapa perhitungan antara lain:

1. Menghitung momen gaya pada saat pemindahan sparepart di nyatakan aman atau beresiko saat kerja tersebut.

2. Menghitung data RWL dan LI yang di ambil dari beberapa pengukuran yaitu, faktor pengali horizontal (HM), faktor pengali vertikal (VM), faktor pengali jarak (DM), faktor pengali asimetri (AM), faktor pengali frekuensi (FM), faktor pengali pegangan (HM) [13].

Data diambil aktivitas pemindahan sparepart seberat $20 \mathrm{~kg}$ secara manual, pekerja yang diamati sebanyak 4 orang, data yang diambil meliputi berat badan pekerja, berat beban yang diangkat, panjang segmen tubuh panjang telapak tangan, lengan atas, lengan bawah, punggung, sudut inklinasi perut terhadap horizontal dan sudut inklinasi paha terhadap horizontal [14]. 
Tabel 2. Rekapitulasi Hasil Perhitungan RWL

\begin{tabular}{|c|c|c|c|c|c|c|c|c|c|c|}
\hline Operator & Metode & Lokasi & LC & HM & VM & DM & $\mathbf{A M}$ & FM & $\mathbf{C M}$ & RWL \\
\hline \multirow{2}{*}{1} & \multirow{2}{*}{ Pemindahan } & Origin & 23 & 0,8333 & 0,8110 & 0,8616 & 1 & 0,84 & 0,90 & 10,1245 \\
\hline & & Destination & 23 & 0,6250 & 0,8650 & 0,8616 & 1 & 0,84 & 0,90 & 8,0993 \\
\hline \multirow{2}{*}{2} & \multirow{2}{*}{ Pemindahan } & Origin & 23 & 0,8333 & 0,8110 & 0,8616 & 1 & 0,84 & 0,90 & 10,1245 \\
\hline & & Destination & 23 & 0,6250 & 0,8650 & 0,8616 & 0,9988 & 0,84 & 0,90 & 8,0896 \\
\hline \multirow{2}{*}{3} & \multirow{2}{*}{ Pemindahan } & Origin & 23 & 0,7142 & 0,8110 & 0,8616 & 1 & 0,84 & 0,90 & 8,6775 \\
\hline & & Destination & 23 & 0,5555 & 0,8650 & 0,8616 & 0,9983 & 0,84 & 0,90 & 7.1866 \\
\hline \multirow{2}{*}{4} & \multirow{2}{*}{ Pemindahan } & Origin & 23 & 0,8333 & 0,8110 & 0,8616 & 1 & 0,84 & 0,90 & 10,1245 \\
\hline & & Destination & 23 & 0,6250 & 0,8650 & 0,8616 & 0,9997 & 0,84 & 0,90 & 8,0969 \\
\hline
\end{tabular}

Tabel 3. Rekapitulasi Hasil Perhitungan Lifting Index (LI)

\begin{tabular}{|c|c|c|c|c|c|}
\hline Operator & Metode & Lokasi Tangan & Beban (kg) & LI & Keterangan LI \\
\hline \multirow{2}{*}{1} & \multirow{2}{*}{ Pemindahan } & Origin & \multirow{2}{*}{20} & 1.9754 & Mengandung Risiko \\
\hline & & Destination & & 2,4693 & Mengandung Risiko \\
\hline \multirow{2}{*}{2} & \multirow{2}{*}{ Pemindahan } & Origin & \multirow{2}{*}{20} & 1.9754 & Mengandung Risiko \\
\hline & & Destination & & 2,4723 & Mengandung Risiko \\
\hline \multirow{2}{*}{3} & \multirow{2}{*}{ Pemindahan } & Origin & \multirow{2}{*}{20} & 2,3048 & Mengandung Risiko \\
\hline & & Destination & & 2,7829 & Mengandung Risiko \\
\hline 4 & Pemindahan & Origin & 20 & 1.9754 & Mengandung Risiko \\
\hline
\end{tabular}

Dari hasil perhitungan RWL dan LI di atas bisa dilihat hasil tabel rekapitulasinya setiap pekerja pemindahan sparepart tampak bahwa posisi awal dan posisi akhir kurang dari beban aktual sebesar $20 \mathrm{~kg}$. Dan untuk nilai LI pada setiap pekerja pemindahan sparepart tampak bahwa lebih dari $1(\mathrm{~L} 1>1)$ maka pekerjaan tersebut dikategorikan berhati-hati/tidak aman dapat menimbulkan resiko cedera tulang belakang L5/S1 [15].

\begin{tabular}{cccc}
\multicolumn{4}{c}{ Tabel 4. Rekapitulasi Hasil Perhitungan $\mathrm{Fc}$} \\
\hline Operator & Fc pada L5/S1 $(\mathbf{N})$ & Keterangan & Kategori \\
\hline 1 & 5647,17 & $3500 \mathrm{~N}<\mathrm{Fc}<6500 \mathrm{~N}$ & Berhati-hati \\
2 & 2522,30 & $\mathrm{Fc}<3500 \mathrm{~N}$ & Aman \\
3 & 4595,21 & $3500 \mathrm{~N}<\mathrm{Fc}<6500 \mathrm{~N}$ & Berhati-hati \\
4 & 7645,30 & $\mathrm{Fc}>6500 \mathrm{~N}$ & Berbahaya \\
\hline
\end{tabular}

Berdasarkan hasil diatas menunjukkan besarnya gaya tekan yang terjadi di L5/S1 pada setiap pekerja pada aktivitas pemindahan sparepart. Terlihat bahwa ada operator memiliki gaya tekan (kompresi) di L5/S1 melebihi batas aman (6500) N. Maka dapat disimpulkan bahwa pekerjaan yang dilakukan dalam kategori berhati hati, sehingga mengandung resiko terhadap cedera tulang belakang pada L5/S1.

\section{Kesimpulan}

Dari hasil penelitian analisa aktivitas manual material hadling menggunakan biomekanika dan niosh dapat disimpulkan sebagai berikut : rata rata pekerja memiliki gaya tekan kompresi di L5/S1 diantara 3500 - $6500 \mathrm{~N}$. Berarti ada resiko pada tulang belakang L5/S1, . Apabila hal tersebut terjadi dalam waktu yang lama, maka dapat mengakibatkan rusaknya ruas tulang belakang di L5/S1. Berdasarkan perhitungan Recommended Weight Limit (RWL) nilai RWL kurang dari beban aktual sebesar $20 \mathrm{~kg}$, Untuk nilai LI lebih dari 1 (LI > 1) maka masing-masing pekerja pada pekerjaan tersebut menimbulkan resiko cedera tulang belakang L5/S1 . 


\section{Referensi}

[1] Ayoub, M. M. and Dampsey, P. G. 1999. The Psychophysical Approach to Material Handling Task Design. Ergonomic Vol. 42. No. 1, pp: 17 -31 .

[2] Bambang suhardi. Perancangan system kerja. Cetakan 1 Surakarta. UPT UNS Press. 2015.

[3] Chaffin, D.B. and Park, K.S., A lonitudinal Study of low back pain as associated with Occupational lifting factors, American Industrial Hygiene Association Journal, 1973, v 34, p.513

[4] Chaffin D.B and Anderson G.B.J. 1991. Occupational Biomechanic. John Wiley and Sons Inc. New York.

[5] Hardianto Iridiastadi. Yassierli. Ergonomi suatu pengantar, PT. Remaja Rosdaya. Bandung. 2014.

[6] Kroemer and Elbert. 1994. Ergonomics, How to Design For Ease and Efficiency. London: Taylor and Francis.

[7] Kroemer, Karl H.E., Kroemer, Anne D., 2001, Office Ergonomics, New York, Taylor \& Francis

[8] McCormick,E.J and M.S. Sanders. Human factor in Engineering and design. New York: McGraw Hill Book Company, 1994.

[9] NIOSH. 1994. Applications Manual For The Revised NIOSH Lifting Equation diambil di internet di alamat http://www.cdc.gov/niosh

[10] Nurmianto, Eko; 2004. Ergonomi, Konsep Dasar dan Aplikasinya, Edisi Kedua, PT. Guna Widya, Surabaya.

[11] Peraturan Menteri Tenaga kerja dan Transmigrasi R.I. No. Per 03/MEN/1978. Tentang Penunjukan dan Wewenang, Serta Kewajiban Pegawai pengawas Keselamatan dan Kesehatan Kerja dan Ahli Keselamatan Kerja.

[12] Tarwaka, Solichul, Sudiajeng , L. Ergonomi Untuk Keselamatan, Kesehatan Kerja dan Produktivitas, Uniba Press, Surakarta, 2004.

[13] Waters, T. R.; Anderson, V. P.; Garg, A. 1994. Application Manual For The Revised NIOSH Lifting Equation. US Department of Health and Human Service, Cincinnati.

[14] Waters, T. R.; Anderson, V. P.; Garg, A., Fine, J. 1993. Revised NIOSH Equation for the Design and Evaluation of Manual Lifting Task. National Institute for Occupational Safety and Health, Cincinnati.

[15] WignjoSoebroto ，Sritomo; 1995. Ergonomi Studi Gerak dan Waktu. Edisi pertama, PT.Guna Widya, Jakarta 